\title{
Hydrogen Evolution Reaction Property in Alkaline Solution of Molybdenum Disulfide Modified by Surface Anchor of Nickel-Phosphorus Coating
}

\author{
Jun He, Laizhou Song *, Jiayun Yan, Ning Kang, Yingli Zhang and Wei Wang \\ School of Environmental and Chemical Engineering, Yanshan University, Qinhuangdao 066004, China; \\ hejun@ysu.edu.cn (J.H.); yanjiayun0327@163.com (J.Y.); m18332559448@163.com (N.K.); \\ m15032367859@163.com (Y.Z.); ww18332559496@163.com (W.W.) \\ * Correspondence: songlz@ysu.edu.cn; Tel.: +86-335-838-7741; Fax: +86-335-806-1569 \\ Academic Editor: Mario Fafard
}

Received: 3 May 2017; Accepted: 3 June 2017; Published: 7 June 2017

\begin{abstract}
Molybdenum disulfide $\left(\mathrm{MoS}_{2}\right)$ is unfavorable for practical application in the hydrogen evolution reaction (HER) process due to its inert basal surface, inferior conductivity, and limited amount of active edge sites. For the purpose of enhancing the HER performance of this catalyst, the HER activity of its basal surface should be increased. Herein, three types of nickel-phosphorus (Ni-P) coatings-namely, low phosphorus (LP), medium phosphorus (MP) and high phosphorus (HP) -were anchored onto the surfaces of $\mathrm{MoS}_{2}$ nanoparticles via an electroless plating process; thus, three $\mathrm{Ni}-\mathrm{P} / \mathrm{MoS}_{2}$ composites $\left(\mathrm{Ni}-\mathrm{LP} / \mathrm{MoS}_{2}, \mathrm{Ni}-\mathrm{MP} / \mathrm{MoS}_{2}\right.$, and $\left.\mathrm{Ni}-\mathrm{HP} / \mathrm{MoS}_{2}\right)$ were fabricated. Crystal structures, morphologies, chemical components, and HER performances of each in an alkaline solution were characterized. Both Ni-LP/MoS ${ }_{2}$ and Ni-MP/MoS ${ }_{2}$ showed a crystal nature, while the amorphous feature for $\mathrm{Ni}-\mathrm{HP} / \mathrm{MoS}_{2}$ was validated. The three $\mathrm{Ni}-\mathrm{P} / \mathrm{MoS}_{2}$ composites exhibited a higher HER activity than the pure $\mathrm{MoS}_{2}$. The HER performance of the Ni-MP/MoS 2 composite was more outstanding than those of other two composites, which could be attributed to the presence of metastable nickel phosphides, and the excellent conductivity of Ni-MP coating anchored on the basal surface of $\mathrm{MoS}_{2}$.
\end{abstract}

Keywords: hydrogen evolution reaction; molybdenum disulfide; nickel-phosphorus coating; electroless plating; alkaline electrolyte

\section{Introduction}

Hydrogen as a charming and clean energy carrier has received tremendous attention to relieve the energy crisis and environmental problems caused by the consumption of traditional fossil fuels [1]. In general, the electrocatalytic hydrogen evolution reaction (HER) process is extensively employed for the generation of hydrogen. The well-known platinum $(\mathrm{Pt})$ and $\mathrm{Pt}$-based alloys possess a superior electrocatalytic HER property [2,3], but the limited availability and high price retard their large-scale applications. In view of this situation, the exploitation of cost-effective and earth-abundant alternatives of Pt-based catalysts is very crucial to push the engineering practice of HER.

Until present, carbides [4], borides [5], selenides [6], nitrides [7], phosphides [8], as well as transition metal sulfides [9] have been recommended as HER catalysts. Among them, molybdenum disulfide $\left(\mathrm{MoS}_{2}\right)$ can be identified as a promising alternative because of the earth-abundant and low-cost advantages, and the passable electrocatalytic property of this material. Nevertheless, the defects of inert basal plane, insufficient edge sites, and the inferior electron-transport feature of $\mathrm{MoS}_{2}$ restrict its HER performance [10,11]. Conventionally, there are three approaches employed to promote the HER activity of $\mathrm{MoS}_{2}$ : (i) increasing the active number of edge sites, (ii) enhancing 
the activity of active sites, and (iii) improving electrical conductivity within the interparticle and interdomain. Thus, numerous attempts-including interlayer intercalation [12,13], gentle oxidation [14,15], phase transformation (from $2 \mathrm{H}-\mathrm{MoS}_{2}$ to $1 \mathrm{~T}-\mathrm{MoS}_{2}$ ) [16,17], functional structural design [10,18], as well as stabilizing the edge layers with organic molecules [19] — have been made for enhancing the HER property of $\mathrm{MoS}_{2}$. Also, the improvement in the electrical contact between the active sites has been attempted, and various promoters such as gold [12], carbon materials [20], core-shell $\mathrm{MoO}_{3}$ [21], graphene [22,23], graphene oxide [24,25], and nickel-phosphorus powders [26] have been applied as electrical conduction supports to improve the electrical contact between active sites of $\mathrm{MoS}_{2}$.

With respect to the reported efforts mentioned above, unquestionably, attempts made for the increase in abundant active sites, the increment in stacked height along the (002) basal plane aiming to gain a maximum value of edge/basal ratio, and the enhancement in electrical conductivity within the interparticle and interdomain are valuable for the enhancement in HER performance of $\mathrm{MoS}_{2}$. However, for this catalyst, the enhancement in HER property of its inert basal plane has not been comprehensively attempted. The electroless nickel-phosphorus (Ni-P) coating possesses merits such as facile fabrication, wear resistance, anticorrosion, excellently electrical conductivity, and promising HER activity, so the anchor of Ni-P coating onto the inert basal plane may be competent for the enhancement in HER performance of $\mathrm{MoS}_{2}$. To date, according to our best knowledge so far, the electroless Ni-P coating anchored onto the surface of $\mathrm{MoS}_{2}$ to enhance the HER property of this catalyst has not been attempted. In this sense, this work will offer a novel sight for the enhancement in HER property of $\mathrm{MoS}_{2}$.

The purpose of this research is to reveal the effect of Ni-P coatings with different phosphorus content on the HER activity of $\mathrm{MoS}_{2}$. Three Ni-P coatings, i.e., low phosphorus (Ni-LP), medium phosphorus (Ni-MP), and high phosphorus (Ni-HP) coatings were anchored onto the surface of $\mathrm{MoS}_{2}$ by an electroless plating process. Three Ni-P/MoS 2 composites (Ni-LP/MoS, $\mathrm{Ni}-\mathrm{MP} / \mathrm{MoS}_{2}$, and Ni-HP/MoS 2 ) were fabricated. Morphologies, structures, compositions, and crystallinities of these three $\mathrm{Ni}-\mathrm{P} / \mathrm{MoS}_{2}$ composites were characterized by scanning electron microscope (SEM), energy dispersive spectrometry (EDS), X-ray diffraction (XRD), and X-ray photoelectron spectroscopy (XPS). Also, the HER properties of them in $1 \mathrm{~mol} / \mathrm{L} \mathrm{KOH}$ solution were evaluated using linear sweep voltammetry (LSV), Tafel polarization, cyclic voltammetry (CV), and electrochemical impedance spectroscopy (EIS).

\section{Experimental Details}

\subsection{Material}

The analytical grade reagents including ammonium molybdate tetrahydrate $\left(\left(\mathrm{NH}_{4}\right)_{6} \mathrm{Mo}_{7} \mathrm{O}_{24} \cdot 4 \mathrm{H}_{2} \mathrm{O}, 99 \mathrm{wt} \%\right)$, thiourea $\left(\mathrm{CH}_{4} \mathrm{~N}_{2} \mathrm{~S}, 99 \mathrm{wt} \%\right)$, nickel sulfate hexahydrate $\left(\mathrm{NiSO}_{4} \cdot 6 \mathrm{H}_{2} \mathrm{O}\right)$, citric acid monohydrate $\left(\mathrm{C}_{6} \mathrm{H}_{8} \mathrm{O}_{7} \cdot \mathrm{H}_{2} \mathrm{O}\right)$, sodium hypophosphite monohydrate $\left(\mathrm{NaH}_{2} \mathrm{PO}_{2} \cdot \mathrm{H}_{2} \mathrm{O}\right)$, succinic acid $\left(\mathrm{C}_{4} \mathrm{H}_{6} \mathrm{O}_{4}\right)$, ammonium hydrogen fluoride $\left(\mathrm{NH}_{4} \mathrm{HF}\right)$, sodium acetate trihydrate $\left(\mathrm{NaAc} \cdot 3 \mathrm{H}_{2} \mathrm{O}\right)$, ammonia solution $(25 \mathrm{wt} \%)$, potassium hydroxide $(\mathrm{KOH})$, hydrochloric acid (36.5 wt \%), N, N-dimethylacetamide (DMAc), palladium chloride $\left(\mathrm{PdCl}_{2}\right)$ powder, and stannous chloride dehydrate $\left(\mathrm{SnCl}_{2} \cdot 2 \mathrm{H}_{2} \mathrm{O}\right)$ were purchased from Jingchun Scientific Co. Ltd. (Shanghai, China). All of them were used as received and without further purification. The $5 \mathrm{wt} \%$ of Nafion solution was supplied by Alfa Aesar Chemicals Co. Ltd. (Shanghai, China). The Pt/C power (20 wt $\% \mathrm{Pt}$ on Vulcan XC-72R) was provided by Yu Bo Biotech Co. Ltd. (Shanghai, China).

\subsection{Preparation and Pretreatment of $\mathrm{MoS}_{2}$}

Firstly, $1.41 \mathrm{~g}$ of $\left(\mathrm{NH}_{4}\right)_{6} \mathrm{Mo}_{7} \mathrm{O}_{24} \cdot 4 \mathrm{H}_{2} \mathrm{O}$ and $0.26 \mathrm{~g}$ of $\mathrm{CH}_{4} \mathrm{~N}_{2} \mathrm{~S}$ were dissolved in $20 \mathrm{~mL}$ of deionized water, then this mixed solution was vigorously stirred for $5 \mathrm{~min}$ and followed by transfer to a $25 \mathrm{~mL}$ Teflon-lined stainless steel autoclave placed in an electric cooker (WRN-010, Eurasian, Tianjin, China). Afterward, the temperature of this cooker was increased from room temperature to $200{ }^{\circ} \mathrm{C}$ and kept this temperature for $24 \mathrm{~h}$. After the reaction, the temperature of electric cooker was naturally cooled to ambient 
temperature, then the mixed solution was centrifuged and the obtained $\mathrm{MoS}_{2}$ powders were washed with deionized water. Finally, $\mathrm{MoS}_{2}$ powders were dried at $60^{\circ} \mathrm{C}$ under a vacuum atmosphere condition.

The pretreatment process of synthesized $\mathrm{MoS}_{2}$ powder was as follows: $15 \mathrm{mg}$ of $\mathrm{MoS}_{2}$ powder was dispersed in $75 \mathrm{~mL}$ of DMAc by stirring, then the suspend solution was ultrasonically treated for $22 \mathrm{~h}$ using a ultrasonic cleaner (KQ-500DB, Kunshan Ultrasonic Apparatus Co. Ltd., Kunshan, China). After that, this suspended solution was added into $10 \mathrm{~mL} 50 \mathrm{~g} / \mathrm{L}$ of $\mathrm{SnCl}_{2}$ solution ( $\mathrm{pH}$ of the $\mathrm{SnCl}_{2}$ solution was previously adjusted to 1 using hydrochloric acid), and the mixed solution was ultrasonically dispersed for $10 \mathrm{~min}$. Then the $\mathrm{MoS}_{2}$ powders were collected and washed with deionized water adequately. Subsequently, the washed powders were ultrasonically dispersed in $5 \mathrm{~mL}$ of activation solution (containing $1 \mathrm{mg}$ of $\mathrm{PdCl}_{2}$ ) for $20 \mathrm{~min}$; $\mathrm{pH}$ of this activation solution was previously adjusted to 2 using hydrochloric acid. At last, the treated $\mathrm{MoS}_{2}$ powders was centrifugally collected and washed five times with deionized water, and followed by dried in a desiccator ( DL-101, Zhonghuan Electric Furnace Co. Ltd., Tianjin, China).

\subsection{Synthesis of $\mathrm{Ni}-\mathrm{P} / \mathrm{MoS}_{2}$ Composites}

The composition of the electroless Ni-P bath was shown as that: $30 \mathrm{~g} / \mathrm{L}$ of $\mathrm{NiSO}_{4} \cdot 6 \mathrm{H}_{2} \mathrm{O}, 20 \mathrm{~g} / \mathrm{L}$ of $\mathrm{C}_{6} \mathrm{H}_{8} \mathrm{O}_{7} \cdot \mathrm{H}_{2} \mathrm{O}, 15 \mathrm{~g} / \mathrm{L}$ of NaAc, $5 \mathrm{~g} / \mathrm{L}$ of $\mathrm{C}_{4} \mathrm{H}_{6} \mathrm{O}_{4}, 5 \mathrm{~g} / \mathrm{L}$ of $\mathrm{NH}_{4} \mathrm{HF}$, and $7.5 \mathrm{~g} / \mathrm{L}$ of $\mathrm{NaH}_{2} \mathrm{PO}_{2} \cdot \mathrm{H}_{2} \mathrm{O}$ for Ni-LP plating (15 g/L for Ni-MP and $30 \mathrm{~g} / \mathrm{L}$ for Ni-HP). When all added reagents were dissolved in deionized water, $\mathrm{pH}$ of the solution was adjusted to $4.8-5.0$ by the dropwise addition of ammonia solution. After that, the solution temperature was increased from room temperature to $85 \pm 2{ }^{\circ} \mathrm{C}$, and $5 \mathrm{mg}$ of pretreated $\mathrm{MoS}_{2}$ powders were put into $200 \mathrm{~mL}$ of $\mathrm{Ni}-\mathrm{P}$ bath; the plating process lasted for $30 \mathrm{~min}$. As the plating process finished, the prepared $\mathrm{Ni}-\mathrm{P} / \mathrm{MoS}_{2}$ powders were collected and washed with deionized water. Finally, the collected powders were dried at $60{ }^{\circ} \mathrm{C}$ in a vacuum oven (DZF-6050, Boxun Industrial Co. Ltd., Shanghai, China) Thus, three Ni-P/MoS 2 composites (denoted as $\mathrm{Ni}-\mathrm{LP} / \mathrm{MoS}_{2}, \mathrm{Ni}-\mathrm{MP} / \mathrm{MoS}_{2}$ and $\mathrm{Ni}-\mathrm{HP} / \mathrm{MoS}_{2}$ ) were fabricated.

\subsection{Characterization}

Crystal structures of the synthesized $\mathrm{Ni}-\mathrm{P} / \mathrm{MoS}_{2}$ composites were characterized by an $\mathrm{X}$-ray diffractometer (XRD, SmartLab, Tokyo, Japan) using $\mathrm{Cu} \mathrm{K} \alpha$ radiation $(\lambda=1.5418 \AA$ ) with a scan rate of $2^{\circ}(2 \theta) /$ s. Morphologies of the composites were observed using a scanning electron microscope (SEM, S-4800, Hitachi, Tokyo, Japan) with an accelerating voltage of $5 \mathrm{kV}$. Compositions of the three $\mathrm{Ni}-\mathrm{P} / \mathrm{MoS}_{2}$ samples were determined by an energy-dispersive X-ray spectrometry (EDS) attached to the scanning electron microscope mentioned above. The X-ray photoelectron spectra (XPS, ESCALAB MK II, Thermo Fisher Scientific, Waltham, MA, USA) of the fabricated composites were characterized with $\mathrm{Mg} \mathrm{K} \alpha$ as the excitation source; the binding energy was calibrated by that of the $\mathrm{C} 1 \mathrm{~s}$ peak at $284.6 \mathrm{eV}$ derived from the graphitic carbon.

\subsection{Electrochemical Measurements}

$5 \mathrm{mg}$ of $\mathrm{Ni}-\mathrm{P} / \mathrm{MoS}_{2}$ catalyst and $50 \mu \mathrm{L}$ of Nafion solution were ultrasonically dispersed in $1 \mathrm{~mL}$ of solution consisting of $250 \mu \mathrm{L}$ ethanol and $750 \mu \mathrm{L}$ deionized water for $30 \mathrm{~min}$ to obtain a homogeneous slurry. Subsequently, $5 \mu \mathrm{L}$ of the slurry was dropped onto a glassy carbon electrode (GCE, $3 \mathrm{~mm}$ in diameter, the catalyst load was $\sim 0.337 \mathrm{mg} / \mathrm{cm}^{2}$ ). The well-known $\mathrm{Pt} / \mathrm{C}$ catalyst was also loaded to another GCE for comparison in HER property. Before the electrochemical tests, all electrodes naturally dried at room temperature.

All electrochemical tests were conducted by an electrochemical workstation (CHI 650C, Chenhua Co. Ltd, Shanghai, China) in a $1.0 \mathrm{~mol} / \mathrm{L}$ of $\mathrm{KOH}$ electrolyte. A standard three-electrode system was employed, where the GCE bearing the synthesized Ni-P/MoS $\mathrm{M}_{2}$ composite $\left(\mathrm{MoS}_{2}\right.$ or Pt/C) acted as the working electrode, a platinum foil served as the counter electrode and a $\mathrm{Ag} / \mathrm{AgCl}$ electrode employed as the reference electrode. The pure $\mathrm{N}_{2}$ gas was purged into the solution for 30 min to degas the dissolved oxygen before the tests. The obtained potentials related to the $\mathrm{Ag} / \mathrm{AgCl}$ electrode 
were calibrated to the reversible hydrogen electrode (RHE) scale: $E_{\mathrm{RHE}}=E_{\mathrm{Ag} / \mathrm{AgCl}}+0.059 \mathrm{pH}+$ $0.209 \mathrm{~V}$. Linear sweep voltammetry (LSV) was carried out at a scan rate of $2 \mathrm{mV} / \mathrm{s}$ with the potential ranging from -0.3 to $0.8 \mathrm{~V}$ (vs. RHE). Tafel polarization curves were obtained with a potential window of $0.3 \sim 1.5 \mathrm{~V}$ (vs. RHE) at a scan rate of $10 \mathrm{mV} / \mathrm{s}$. Cyclic voltammetry (CV) measurements were conducted at a scan rate of $10 \mathrm{mV} / \mathrm{s}$ with the potential in the range of -0.6 and $0.2 \mathrm{~V}$ (vs. RHE). The electrochemical impedance spectroscopy (EIS) measurements were conducted at a cathodic overpotential of $0.7 \mathrm{~V}$ (vs. RHE) with the frequency ranging from $10^{5}$ to $0.01 \mathrm{~Hz} ; 5 \mathrm{mV}$ of the sinusoidal signal was employed. To guarantee the reproducibility of the experimental data, all measurements were performed in triplicate.

\section{Results and Discussion}

\subsection{Characterizations of $\mathrm{Ni}-\mathrm{P} / \mathrm{MoS}_{2}$ Composites}

\subsubsection{X-ray Diffraction (XRD) Analysis}

The XRD patterns of the pure $\mathrm{MoS}_{2}$ and three Ni-P/MoS 2 composites were displayed in Figure 1. For the pure $\mathrm{MoS}_{2}$ sample, three characteristics peaks at $2 \theta=9.8^{\circ}, 33.5^{\circ}$, and $58.4^{\circ}$ corresponding to (002), (100), and (110) crystal planes of hexagonal $\mathrm{MoS}_{2}$ can be observed. The diffraction peak at $2 \theta=9.8^{\circ}$ is correlated to the stacked layers of $\mathrm{MoS}_{2}$ along the c axis, indicating the cumulated structure for the (002) plane during the hydrothermal process. In contrast with that of the pure $\mathrm{MoS}_{2}$, the dispersive peaks for $\mathrm{Ni}-\mathrm{LP} / \mathrm{MoS}_{2}$ composite are identified as follows: $44.4^{\circ}$ for $\mathrm{Ni}_{12} \mathrm{P}_{5}, 30.1^{\circ}$ and $36.1^{\circ}$ for $\mathrm{Ni}_{5} \mathrm{P}_{4} ; 41.9^{\circ}, 43.2^{\circ}$, and $68.1^{\circ}$ for $\mathrm{Ni}_{5} \mathrm{P}_{2}$; and $46.6^{\circ}$ and $51.8^{\circ}$ for $\mathrm{Ni}_{3} \mathrm{P}$. As for the $\mathrm{XRD}$ pattern of $\mathrm{Ni}-\mathrm{MP} / \mathrm{MoS}_{2}$, the detected peaks are ascribed as that: $28.9^{\circ}$ and $32.0^{\circ}$ for $\mathrm{Ni}_{5} \mathrm{P}_{4} ; 36.8^{\circ}$ for $\mathrm{NiP} ; 40.8^{\circ}$ and $55.0^{\circ}$ for $\mathrm{Ni}_{2} \mathrm{P}$; and $46.6^{\circ}$ for $\mathrm{Ni}_{3} \mathrm{P}$. The presence of nickel phosphides would be helpful for the enhancement in HER of the composite [27]. Both Ni-LP/MoS 2 and Ni-MP/MoS 2 composites remain the crystal features of the corresponding Ni-P coatings; but the crystallinity of Ni-LP/ $/ \mathrm{MoS}_{2}$ is higher than that of Ni-MP $/ \mathrm{MoS}_{2}$. For the Ni-LP/ $\mathrm{MoS}_{2}$ composite, intensities of peaks at $2 \theta=44.7^{\circ}, 51.9^{\circ}$, and $76.3^{\circ}$ corresponding to (111), (200), and (220) planes of the fcc nickel become very weak, which may be due to the thin thickness of Ni-LP coating and the insufficient covering of nickel phosphides. However, for the Ni-MP/MoS 2 composite, these three peaks mentioned above can be easily identified. In addition, for Ni-LP/MoS 2 and Ni-MP/MoS 2 composites, the trace signal of $\mathrm{MoS}_{2}$ can still be found, suggesting that Ni-LP and Ni-MP coatings do not cover the surface of $\mathrm{MoS}_{2}$ completely. Thus, $\mathrm{Ni}-\mathrm{LP} / \mathrm{MoS}_{2}$ and Ni-MP/MoS 2 composites show the mixed crystal characteristics (consisting of crystalline or microcrystalline, and amorphous phases). The presence of mixed crystal phases will be helpful for the electrocatalytic HER activity $[10,28]$. For the Ni-HP/MoS 2 composite compared with other two composites, only one obvious broad peak at $2 \theta=44.7^{\circ}$ is easily observed, so the amorphous structure of this composite is validated. The (111) reflection of fcc nickel becomes broadened with the increase in the phosphorus content of Ni-P coating ( 0.05 at $\%$ of $\mathrm{P}$ for Ni-LP, 7.37 at $\%$ of $\mathrm{P}$ for Ni-MP, and 11.25 at $\%$ of $\mathrm{P}$ for $\mathrm{Ni}-\mathrm{HP})$. The increasing phosphorus content of $\mathrm{Ni}-\mathrm{P}$ coating will lead to the increase in lattice disorder and the decrease in crystallinity of the composite. 

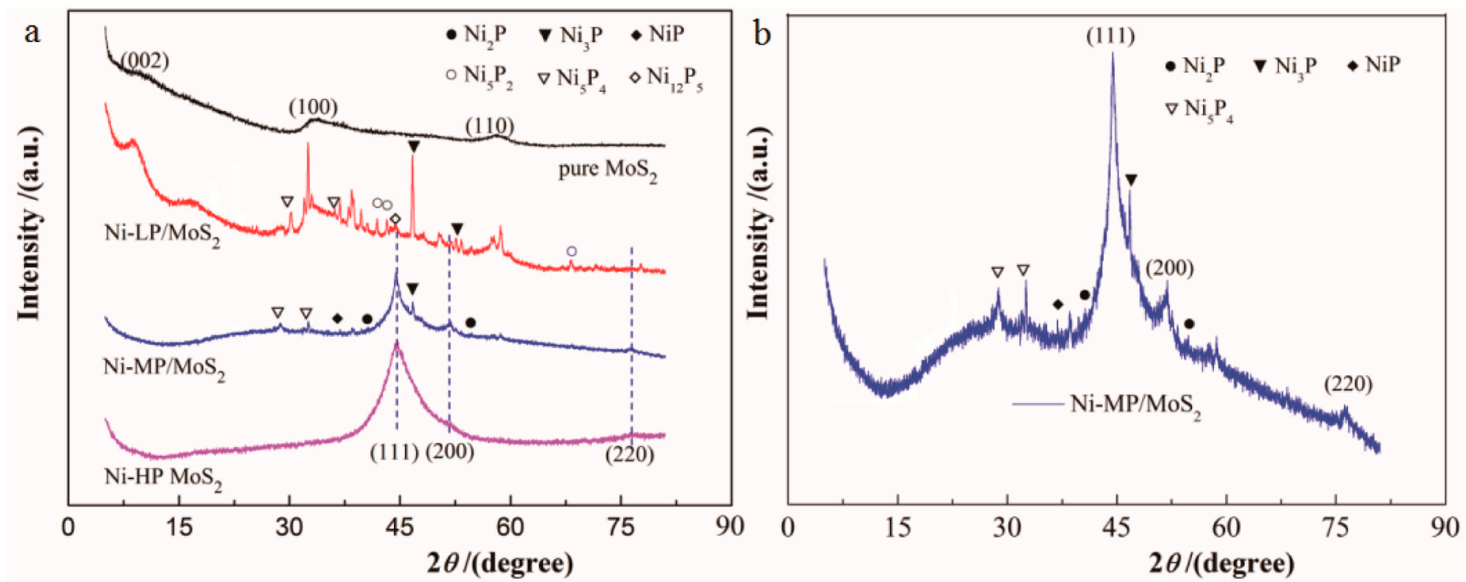

Figure 1. X-ray diffraction (XRD) spectra of the pure $\mathrm{MoS}_{2}$ and three $\mathrm{Ni}-\mathrm{P} / \mathrm{MoS}_{2}$ composites: (a) pure $\mathrm{MoS}_{2}, \mathrm{Ni}-\mathrm{LP} / \mathrm{MoS}_{2}, \mathrm{Ni}-\mathrm{MP} / \mathrm{MoS}_{2}$, and Ni-HP/MoS 2 composites; and (b) Ni-MP/MoS ${ }_{2}$ composite.

\subsubsection{Scanning Electron Microscope (SEM) and Energy Dispersive Spectrometry (EDS)}

SEM images of the pristine $\mathrm{MoS}_{2}$ and the three Ni-P/MoS 2 composite samples are presented in Figure 2. The $\mathrm{MoS}_{2}$ sample shows a nanoflower-like morphology (Figure 2a). As for the Ni-LP/MoS composite, the morphology (Figure 2b) of this sample is similar to that of $\mathrm{MoS}_{2}$, but some scattered agglomerates stacking on the surfaces of $\mathrm{MoS}_{2}$ particles can be found. The nanoflower-like morphology corresponding to $\mathrm{MoS}_{2}$ can still be detected, suggesting that the Ni-LP coating does not cover the $\mathrm{MoS}_{2}$ surface completely. For the Ni-MP/MoS 2 composite, the nanoflower-like structure of $\mathrm{MoS}_{2}$ (labeled by a blue rectangle in Figure 2c) cannot readily identified; many plates can be found (described by red circles in Figure 2c), which can be assigned to the deposited Ni-MP particles. Unlike the sample of Ni-LP/MoS 2 , defects (such as void and segregation) existing on the surface of Ni-MP/MoS 2 composite are reduced. The morphology of Ni-MP/MoS 2 different from that of the Ni-LP/MoS could be attributed to the medium crystalline nature of the Ni-MP coating. The smooth, uniform, and cauliflower-like morphology of Ni-HP/ $\mathrm{MoS}_{2}$ composite (Figure 2d) can be observed, indicating the amorphous nature of this composite sample. This can be due to the uniform Ni-HP coating anchored to the surface of $\mathrm{MoS}_{2}$.

EDS spectra of the three $\mathrm{Ni}-\mathrm{P} / \mathrm{MoS}_{2}$ composites were measured, and results are also given in Figure 2. Compared with that of $\mathrm{MoS}_{2}$, as demonstrated by Figure 2, except for S, Mo, and O elements, the existence of $\mathrm{Ni}$ and $\mathrm{P}$ elements for the three $\mathrm{Ni}-\mathrm{P} / \mathrm{MoS}_{2}$ composites reveals the anchor of $\mathrm{Ni}-\mathrm{P}$ coatings on the surface of $\mathrm{MoS}_{2}$. The presence of $\mathrm{O}$ element may be assigned to the oxidation of $\mathrm{MoS}_{2}$ particles and Ni-P coatings in air and/or the hydrothermal synthesis process $[29,30]$. The $\mathrm{P}$ and Ni contents (at \%) for both Ni-MP/MoS 2 and Ni-HP/MoS ${ }_{2}$ samples are very higher than that of Ni-LP/ $\mathrm{MoS}_{2}$ sample, and they follow the order of Ni-LP $/ \mathrm{MoS}_{2}<\mathrm{Ni}-\mathrm{MP} / \mathrm{MoS}_{2}<\mathrm{Ni}-\mathrm{HP} / \mathrm{MoS}_{2}$; however, $\mathrm{S}$ and Mo contents for these three composites are in a reverse trend $\left(\mathrm{Ni}-\mathrm{LP} / \mathrm{MoS}_{2}>\right.$ $\left.\mathrm{Ni}-\mathrm{MP} / \mathrm{MoS}_{2}>\mathrm{Ni}-\mathrm{HP} / \mathrm{MoS}_{2}\right)$. This can be explained as the plating rate of Ni-LP bath system being smaller than those of the Ni-MP and Ni-HP systems, because of the low addition of sodium hypophosphite in the Ni-LP bath solution. Generally, plating rates of the three Ni-P plating systems follow the sequence: Ni-HP > Ni-MP > Ni-LP, the thickness of Ni-LP coating will be thinner than those of other two Ni-P coatings. Thus, the overlapped percentage of $\mathrm{MoS}_{2}$ by the Ni-LP coating is smaller than those by Ni-MP and Ni-HP coatings, that is, the exposed sites of $\mathrm{MoS}_{2}$ for Ni-LP/MoS 2 are larger than those for Ni-MP/MoS 2 and Ni-HP/MoS 2 composites. Based on this analysis, for the three Ni-P/MoS 2 composites, we can confirm that the contents of $\mathrm{P}, \mathrm{Ni}, \mathrm{S}$, and Mo elements follow the order mentioned above. 

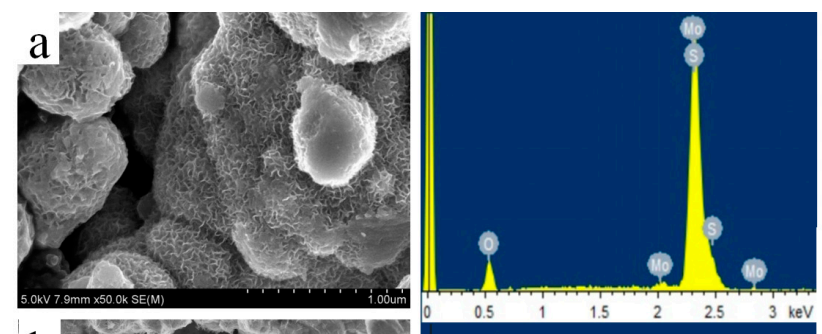

\begin{tabular}{cc}
\hline Element & at \% \\
\hline $\mathrm{O}$ & 49.11 \\
$\mathrm{~S}$ & 31.87 \\
$\mathrm{Mo}$ & 19.02 \\
\hline
\end{tabular}
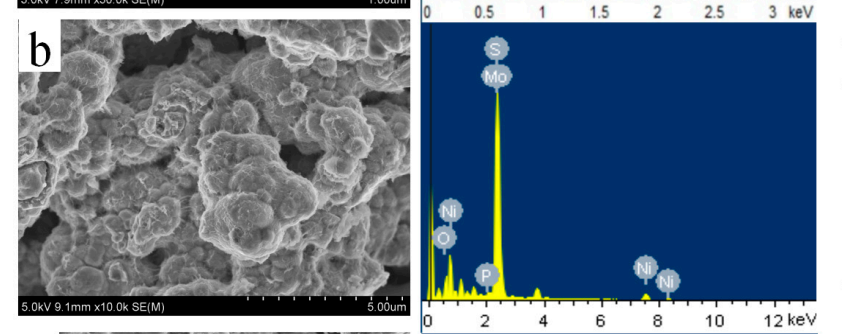

\begin{tabular}{cc}
\hline Element & at \% \\
\hline $\mathrm{O}$ & 62.41 \\
$\mathrm{P}$ & 0.05 \\
$\mathrm{~S}$ & 23.07 \\
$\mathrm{Ni}$ & 3.04 \\
$\mathrm{Mo}$ & 11.43 \\
\hline
\end{tabular}
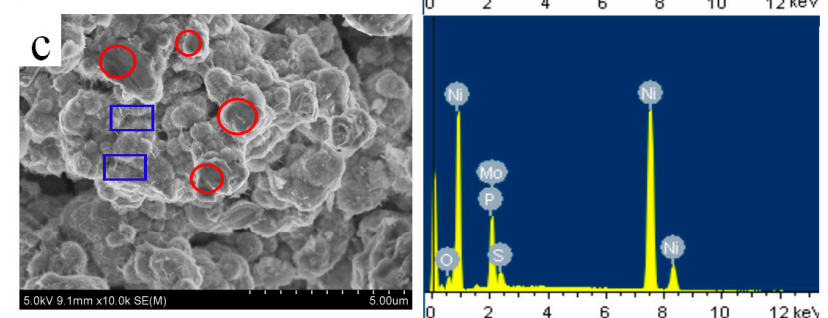

\begin{tabular}{cc}
\hline Element & at \% \\
\hline $\mathrm{O}$ & 19.47 \\
$\mathrm{P}$ & 7.37 \\
$\mathrm{~S}$ & 2.68 \\
$\mathrm{Ni}$ & 69.14 \\
$\mathrm{Mo}$ & 1.34 \\
\hline
\end{tabular}
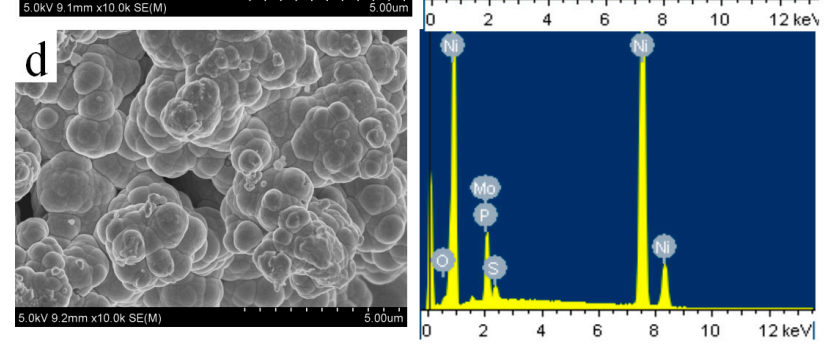

\begin{tabular}{cc}
\hline Element & at \% \\
\hline $\mathrm{O}$ & 3.05 \\
$\mathrm{P}$ & 11.25 \\
$\mathrm{~S}$ & 1.17 \\
$\mathrm{Ni}$ & 83.94 \\
$\mathrm{Mo}$ & 0.59
\end{tabular}

Figure 2. Scanning Electron Microscope (SEM) images and Energy Dispersive Spectrometry (EDS) spectra of the pure $\mathrm{MoS}_{2}$ and three Ni-P/MoS 2 composites: (a) pure $\mathrm{MoS}_{2}$; (b) Ni-LP/MoS ; (c) $\mathrm{Ni}-\mathrm{MP} / \mathrm{MoS}_{2}$; and (d) Ni-HP/ $\mathrm{MoS}_{2}$.

\subsubsection{X-ray Photoelectron Spectroscopy (XPS)}

The elemental compositions and chemical states of the three $\mathrm{Ni}-\mathrm{P} / \mathrm{MoS}_{2}$ composites were characterized by XPS, and results are depicted in Figure 3.

The Mo 3d XPS spectra (Figure 3a) are deconvoluted into six peaks, the two peaks appearing at 226.4 and $232.3 \mathrm{eV}\left(\mathrm{Ni}-\mathrm{LP} / \mathrm{MoS}_{2}\right)$, and 226.1 and $232.0 \mathrm{eV}\left(\mathrm{Ni}-\mathrm{MP} / \mathrm{MoS}_{2}\right)$ can be attributed to the $\mathrm{S} 2 \mathrm{~s}$ of $\mathrm{MoS}_{2}$; the peaks at $229.0 \mathrm{eV}\left(\mathrm{Ni}-\mathrm{LP} / \mathrm{MoS}_{2}\right)$ and $228.8 \mathrm{eV}\left(\mathrm{Ni}-\mathrm{MP} / \mathrm{MoS}_{2}\right)$ correspond to Mo 3d $5 / 2$. Peaks at 232.4 $\mathrm{eV}\left(\mathrm{Ni}-\mathrm{LP} / \mathrm{MoS}_{2}\right), 232.6 \mathrm{eV}\left(\mathrm{Ni}-\mathrm{MP} / \mathrm{MoS}_{2}\right)$ and $232.3 \mathrm{eV}\left(\mathrm{Ni}-\mathrm{HP} / \mathrm{MoS}_{2}\right)$ can be assigned to Mo 3d $3 / 2$, which suggests the existence of Mo(IV) [16]. Moreover, the peaks at $233.2 \mathrm{eV}$ for Ni-LP/MoS $2,232.7 \mathrm{eV}$ for Ni-MP/MoS 2 , and $233.3 \mathrm{eV}$ for Ni-HP/ $\mathrm{MoS}_{2}$ are ascribed to Mo $3 \mathrm{~d}_{5 / 2}$ component [21]. The peaks with a binding energy of $235.7 \mathrm{eV}$ for Ni-LP/ $\mathrm{MoS}_{2}$, and $235.6 \mathrm{eV}$ for the other two composites may be assigned to $\mathrm{MoO}_{3}$ or $\mathrm{MoO}_{4}{ }^{2-}$, indicating the oxidation of these samples [29]. As shown by Figure 3b, with respect to $\mathrm{S} 2 \mathrm{p}$ spectrum, four peaks can be observed for the $\mathrm{Ni}-\mathrm{LP} / \mathrm{MoS}_{2}$ and $\mathrm{Ni}-\mathrm{MP} / \mathrm{MoS}_{2}$; the peaks at 161.8 and $163.7 \mathrm{eV}$ for $\mathrm{Ni}-\mathrm{LP} / \mathrm{MoS}_{2}\left(163.5 \mathrm{eV}\right.$ for Ni-MP/MoS$\left.{ }_{2}\right)$ correspond to the $\mathrm{S} 2 \mathrm{p}_{3 / 2}$ and $\mathrm{S} 2 \mathrm{p}_{1 / 2}$ lines of $\mathrm{MoS}_{2}$, indicating a -2 oxidation state of sulfur. The peak appearing at $162.9 \mathrm{eV}\left(\mathrm{Ni}-\mathrm{LP} / \mathrm{MoS}_{2}\right)$ and $162.5 \mathrm{eV}\left(\mathrm{Ni}-\mathrm{MP} / \mathrm{MoS}_{2}\right)$ may be indexed to $\mathrm{S}_{2} \mathrm{O}_{3}{ }^{2-}$, which can be attributed to the oxidation of sulfur element during the hydrothermal process. The peaks at $170.1 \mathrm{eV}\left(\mathrm{Ni}-\mathrm{LP} / \mathrm{MoS}_{2}\right)$ and $169.1 \mathrm{eV}$ (for Ni-MP/MoS 2 and Ni-HP/MoS 2 ) are identified to the $\mathrm{S}^{4+}$ state in $\mathrm{SO}_{3}{ }^{2-}$, which tends to locate at edges of $\mathrm{MoS}_{2}$ layers [30,31], and also suggesting the oxidation of $\mathrm{MoS}_{2}$. 
As for the Ni 2p spectrum (Figure 3c), peaks observed at $852.9 \mathrm{eV}\left(\mathrm{Ni}-\mathrm{LP} / \mathrm{MoS}_{2}\right.$ and $\left.\mathrm{Ni}-\mathrm{MP} / \mathrm{MoS}_{2}\right)$ and $852.7 \mathrm{eV}\left(\mathrm{Ni}-\mathrm{HP} / \mathrm{MoS}_{2}\right)$ are corresponding to the fcc Ni. For samples of $\mathrm{Ni}-\mathrm{MP} / \mathrm{MoS}_{2}$ and Ni-HP/MoS 2 , the peak at $856.3 \mathrm{eV}$ can be attributed to the oxidized Ni species with a 2+ oxidation state. The peaks with binding energy of $859.8 \mathrm{eV}\left(\mathrm{Ni}-\mathrm{LP} / \mathrm{MoS}_{2}\right), 861.7 \mathrm{eV}\left(\mathrm{Ni}-\mathrm{MP} / \mathrm{MoS}_{2}\right)$, and $861.9 \mathrm{eV}\left(\mathrm{Ni}-\mathrm{HP} / \mathrm{MoS}_{2}\right)$ can be ascribed to the satellite of the $\mathrm{Ni} 2 \mathrm{p}_{3 / 2}$ line [26,27]. Meanwhile, peaks at $873.7 \mathrm{eV}\left(\mathrm{Ni}-\mathrm{MP} / \mathrm{MoS}_{2}\right)$ and $873.8 \mathrm{eV}\left(\mathrm{Ni}-\mathrm{HP} / \mathrm{MoS}_{2}\right)$ can be assigned to oxidized Ni species. Peaks at $879.4 \mathrm{eV}$ for Ni-LP/MoS 2 (879.8 eV for Ni-MP/MoS 2 , and $880.0 \mathrm{eV}$ for Ni-HP/MoS 2 ) are corresponding to the satellite of the Ni $2 p_{1 / 2}$ line [26,27]. For the P $2 p$ spectrum (Figure $3 d$ ), the presence of peak at $128.4 \mathrm{eV}$ for both $\mathrm{Ni}-\mathrm{LP} / \mathrm{MoS}_{2}$ and Ni-MP/MoS 2 composites represents the formation of phosphide [32]; another peak appearing at $133.4 \mathrm{eV}$ for all three $\mathrm{Ni}-\mathrm{P} / \mathrm{MoS}_{2}$ composites suggests the formation of phosphate [33]. Finally, for the three composites, only one peak at $531.7 \mathrm{eV}$ in correlation to the $\mathrm{O} 1 \mathrm{~s}$ can be observed (Figure 3e), indicating the bond formation of $\mathrm{Mo}(\mathrm{IV})-\mathrm{O}$ [15] because of the oxidation.
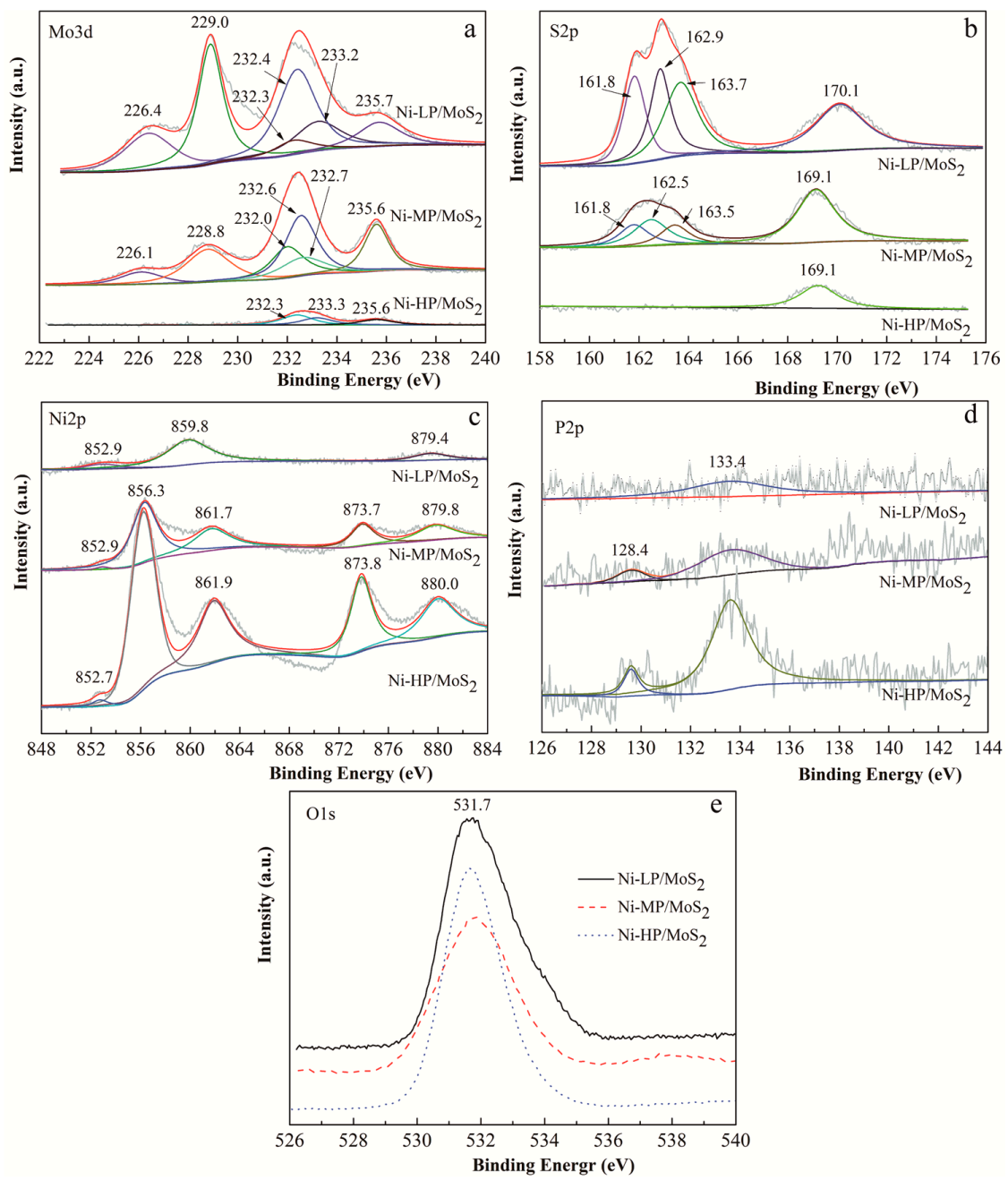

Figure 3. X-ray photoelectron spectra (XPS) of three Ni-P/MoS 2 composites. (a) Mo 3d; (b) S 2p; (c) Ni 2p; (d) P 2p; and (e) O 1s.

\subsection{Hydrogen Evolution Reaction (HER) Performance of the Ni-P/MoS 2 Composite}

\subsubsection{Linear Sweep Voltammetry (LSV)}

LSV curves of all samples $\left(\mathrm{MoS}_{2}, \mathrm{Ni}-\mathrm{LP} / \mathrm{MoS}_{2}, \mathrm{Ni}-\mathrm{MP} / \mathrm{MoS}_{2}, \mathrm{Ni}-\mathrm{HP} / \mathrm{MoS}_{2}\right.$, and $\left.\mathrm{Pt} / \mathrm{C}\right)$ measured at room temperature with a scan rate of $2 \mathrm{mV} / \mathrm{s}$ are presented in Figure 4a; the obtained 
onset overpotentials (OVP) are tabulated in Table 1. Besides, for the purpose of comparison, the LSV curves of Ni-LP, Ni-MP, and Ni-HP samples anchored on the GCE electrodes were measured within a potential window between $-0.4 \mathrm{~V}$ and $0.8 \mathrm{~V}$ (vs. RHE), and the results are presented in Figure $4 \mathrm{~b}$. Among the eight samples, the commercial $\mathrm{Pt} / \mathrm{C}$ shows the best HER activity with a current density of $143 \mathrm{~mA} / \mathrm{cm}^{2}$ (cathodic overpotential is $\sim-70 \mathrm{mV}$ vs. RHE) and a positive OVP ( $360 \mathrm{mV} \mathrm{vs}$. RHE). By contrast, the pure $\mathrm{MoS}_{2}$ exhibits an inferior HER activity because of the more negative OVP than other samples. The HER activities of three Ni-P samples are smaller than those of Ni-MP/MoS 2 and $\mathrm{Ni}-\mathrm{HP} / \mathrm{MoS}_{2}$ composites because of their more negative OVP (vs. RHE) (196 mV for Ni-LP, $214 \mathrm{mV}$ for Ni-MP, $188 \mathrm{mV}$ for Ni-HP). Although HER performances of the three Ni-P/MoS ${ }_{2}$ composites are lower than that of the commercial $\mathrm{Pt} / \mathrm{C}$, they show a more notable HER activity than the sample of $\mathrm{MoS}_{2}$. Of all three Ni-P/MoS 2 composites, the Ni-MP/MoS 2 sample exhibits the best HER activity; the current density of this sample at the cathodic overpotential of $-70 \mathrm{mV}$ (vs. RHE) is $100 \mathrm{~mA} / \mathrm{cm}^{2}$, about $70 \%$ as that of $\mathrm{Pt} / \mathrm{C}$. Also, the OVP value of this sample is higher 475 and $20 \mathrm{mV}$ than those of $\mathrm{Ni}-\mathrm{LP} / \mathrm{MoS}_{2}$ and Ni-HP/MoS . Thus, the Ni-MP/MoS 2 composite will be competent for being a candidate employed in HER.

The HER activity of Ni-LP/MoS 2 is smaller than those of other two composites, this can be due to the fact that the low sodium hypophosphite addition in the plating bath will result in the poor Ni-P deposition, so the enhancement in conductivity of the Ni-LP/MoS 2 composite is inconsiderable. With the increase in the sodium hypophosphite addition (from 7.5 to $15 \mathrm{~g} / \mathrm{L}$ ), the Ni-P coating will be easily obtained and the coating becomes thick, thereby giving rise to a high conductivity of the Ni-MP/MoS composite. Also, the existence of metastable nickel phosphides, particularly the presence of $\mathrm{Ni}_{2} \mathrm{P}$, will be beneficial to the enhancement in electrocatalytic property [34]. Thus, the sample of Ni-MP/MoS reflects a profound HER activity. As the addition of sodium hypophosphite in the bath increases from 15 to $30 \mathrm{~g} / \mathrm{L}$, the amorphous feature of $\mathrm{Ni}-\mathrm{HP} / \mathrm{MoS}_{2}$ composite will exert a detrimental effect on the HER performance (by a comparison of curves 4 and 5 in Figure 4a).
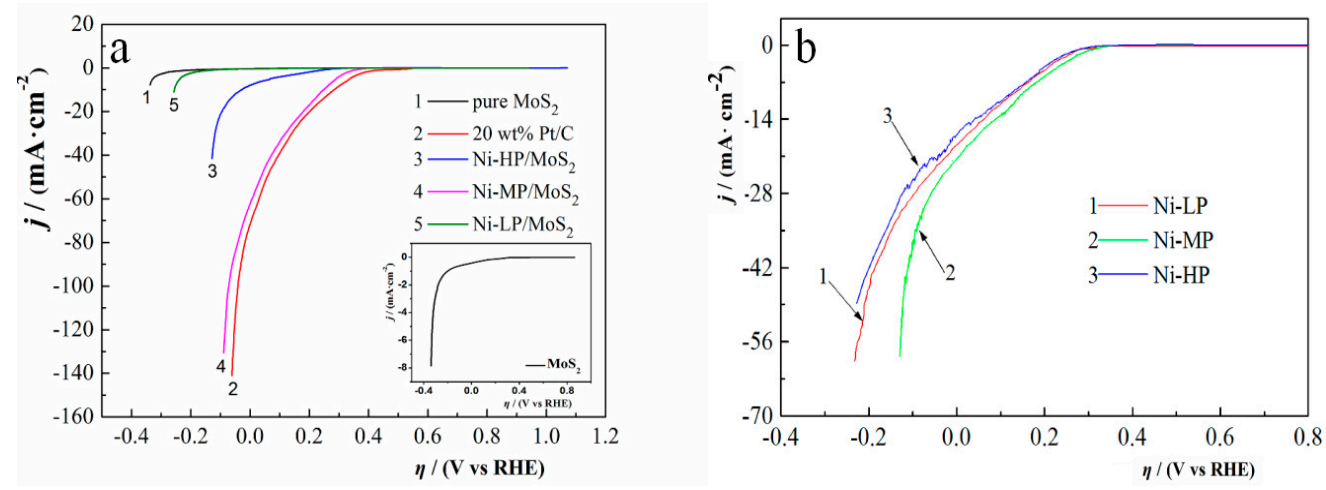

Figure 4. Linear sweep voltammetry (LSV) curves of the samples: (a) pure $\mathrm{MoS}_{2}, 20 \mathrm{wt} \% \mathrm{Pt} / \mathrm{C}$, $\mathrm{Ni}-\mathrm{LP} / \mathrm{MoS}_{2}, \mathrm{Ni}-\mathrm{MP} / \mathrm{MoS}_{2}$, and Ni-HP/MoS 2 . Scan rate: $2 \mathrm{mV} / \mathrm{s}$, potential window: $-0.3 \sim 0.8 \mathrm{~V}$ (vs. RHE); (b) Ni-LP, Ni-MP, and Ni-HP. Scan rate: $2 \mathrm{mV} / \mathrm{s}$, potential window: $-0.4 \sim 0.8 \mathrm{~V}$ (vs. RHE).

Table 1. The obtained values of onset overpotentials (OVP), Tafel slope $(b)$, symmetry factor $(\beta)$, and active site $(n)$.

\begin{tabular}{|c|c|c|c|c|}
\hline Samples & $\mathrm{OVP} /(\mathrm{mV})$ & $b /(m V /$ decade $)$ & $\beta$ & $n /\left(\times 10^{-8} \mathrm{~mol} / \mathrm{cm}^{2}\right)$ \\
\hline $\mathrm{MoS}_{2}$ & -320 & 144 & 0.41 & 0.97 \\
\hline $20 \mathrm{wt} \% \mathrm{Pt} / \mathrm{C}$ & 360 & 52 & 1.14 & 16.8 \\
\hline $\mathrm{Ni}-\mathrm{LP} / \mathrm{MoS}_{2}$ & -155 & 108 & 0.55 & 1.94 \\
\hline $\mathrm{Ni}-\mathrm{MP} / \mathrm{MoS}_{2}$ & 320 & 57 & 1.04 & 2.69 \\
\hline $\mathrm{Ni}-\mathrm{HP} / \mathrm{MoS}_{2}$ & 300 & 70 & 0.84 & 2.28 \\
\hline
\end{tabular}




\subsubsection{Tafel Polarization}

The linear Tafel polarization curves are shown in Figure 5, the relation between overpotential $(\eta)$ and current density $(\log j)$ is illustrated using Equation (1)

$$
\eta=b \times \log j+a
$$

where, $b$ represents the Tafel slope, $a$ is a constant. Moreover, the symmetry factor $(\beta)$ reflecting the HER activity can be calculated by the Tafel slope via Equation (2)

$$
\beta=\frac{2.303 R T}{n_{e} b F}
$$

where, parameters of $R, T, n_{\mathrm{e}}$, and $F$ are corresponding to the gas constant $(8.314 \mathrm{~J} /(\mathrm{K} \cdot \mathrm{mol}))$, absolute temperature, number of exchanged electrons, and the Faraday constant $(96,485 \mathrm{C} / \mathrm{mol})$, respectively. The values of $b$ and $\beta$ derived from the analysis of Figure 5 are also summarized in Table 1 .

A small Tafel slope indicates a high HER activity; as shown by Figure 5, the HER performance of the pure $\mathrm{MoS}_{2}$ is inferior because of the large value of Tafel slope (144 mV/decade). Among the three $\mathrm{Ni}-\mathrm{P} / \mathrm{MoS}_{2}$ samples, the $\mathrm{Ni}-\mathrm{MP} / \mathrm{MoS}_{2}$ composite possesses a minimum $b$ value $(57 \mathrm{mV} /$ decade) very close to that of the $\mathrm{Pt} / \mathrm{C}$ sample $(52 \mathrm{mV} /$ decade), thereby indicating the promising HER performance of this composite. However, values of $b$ for $\mathrm{Ni}-\mathrm{LP} / \mathrm{MoS}_{2}$ and $\mathrm{Ni}-\mathrm{HP} / \mathrm{MoS}_{2}$ composites are 108 and $70 \mathrm{mV} /$ decade, respectively, so their HER performances are lower than that of $\mathrm{Ni}-\mathrm{MP} / \mathrm{MoS}_{2}$ sample [35].

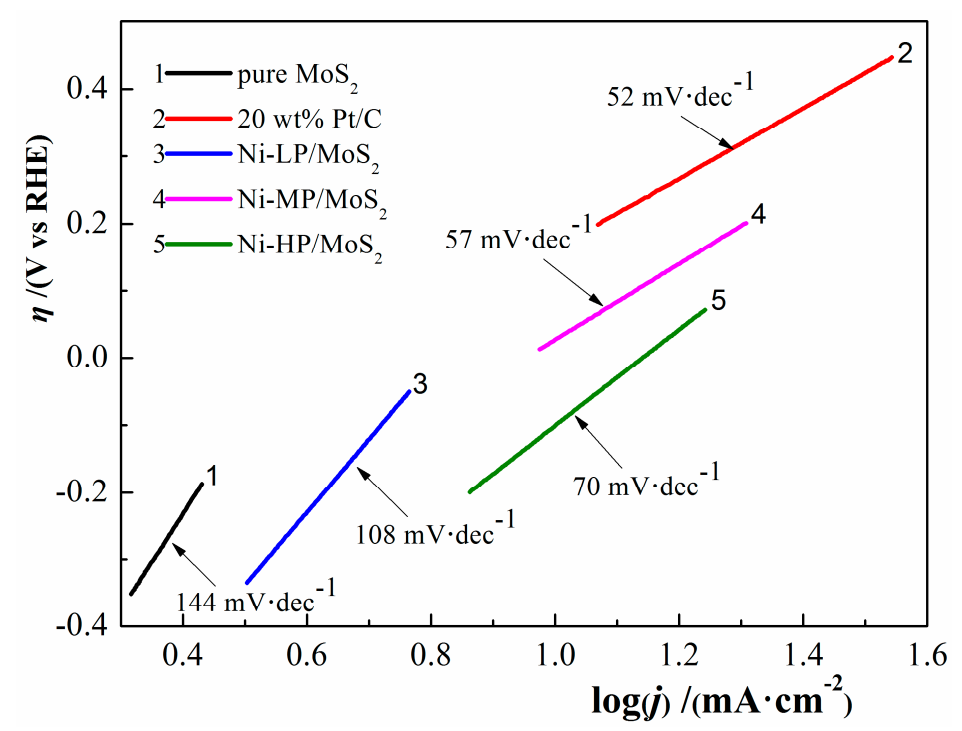

Figure 5. Tafel plots of the pure $\mathrm{MoS}_{2}, 20 \mathrm{wt} \% \mathrm{Pt} / \mathrm{C}, \mathrm{Ni}-\mathrm{LP} / \mathrm{MoS}_{2}, \mathrm{Ni}-\mathrm{MP} / \mathrm{MoS}_{2}$, and Ni-HP/MoS 2 . Scan rate: $10 \mathrm{mV} / \mathrm{s}$, potential window: $0.3 \sim 1.6 \mathrm{~V}$ (vs. RHE).

\subsubsection{Cycle Voltammograms (CV)}

$\mathrm{CV}$ curves of the three $\mathrm{Ni}-\mathrm{P} / \mathrm{MoS}_{2}$ samples were tested within a potential window of -0.6 to $0.2 \mathrm{~V}$ (vs. RHE) at a scan rate of $10 \mathrm{mV} / \mathrm{s}$ (Figure 6a). As indicated byFigure 6a, the oxidation peaks locate at the range from -0.35 to $-0.32 \mathrm{~V}$, while the reduction peaks appear at the potential in the range of $-0.46 \sim-0.37 \mathrm{~V}$. The detected quasi-reversible redox peaks may be related to the processes of electrochemical hydrogen adsorption and electrochemical hydrogen desorption. The CV curves of the pure $\mathrm{MoS}_{2}$ and $\mathrm{Pt} / \mathrm{C}$ samples (inset in Figure 6a) show a similar potential window as those of Ni-P/MoS 2 composites. The peak current density for all samples follows the trend: $\mathrm{MoS}_{2}<$ $\mathrm{Ni}-\mathrm{LP} / \mathrm{MoS}_{2}<\mathrm{Ni}-\mathrm{HP} / \mathrm{MoS}_{2}<\mathrm{Ni}-\mathrm{MP} / \mathrm{MoS}_{2}<\mathrm{Pt} / \mathrm{C}$, revealing the prominent HER performances 
of the commercial $\mathrm{Pt} / \mathrm{C}$ and three $\mathrm{Ni}-\mathrm{P} / \mathrm{MoS}_{2}$ composites. In addition, $\mathrm{CV}$ curves of three $\mathrm{Ni}-\mathrm{P}$ samples were demonstrated in Figure $6 \mathrm{~b}$. These three samples show an oxidation peak at $\sim 0.32 \mathrm{~V}$ and a reduction peak at $\sim 0.38 \mathrm{~V}$. The reduction peak may be assigned to the hydrogen adsorption and desorption processes. The parameter ( $n$, the number of active sites, $\mathrm{mol} / \mathrm{cm}^{2}$ ) embodying the HER activity can be obtained using Equation (3) [36]

$$
n=\frac{Q}{2 F}
$$

where $Q$ is the voltammetric charge $\left(\mathrm{C} / \mathrm{cm}^{2}\right), F$ is the Faraday constant, and the coefficient of 2 represents the fact that two electrons are required to form a hydrogen molecule from two water molecules. In comparison with the value of $n$, HER performances for all samples in Figure 6a with a descending order of $\mathrm{Pt} / \mathrm{C}>\mathrm{Ni}-\mathrm{MP} / \mathrm{MoS}_{2}>\mathrm{Ni}-\mathrm{HP} / \mathrm{MoS}_{2}>\mathrm{Ni}-\mathrm{LP} / \mathrm{MoS}_{2}>\mathrm{MoS}_{2}$ can be attested. For comparison, we also calculated the active number of sites of three Ni-P samples $\left(2.04 \times 10^{-8} \mathrm{~mol} / \mathrm{cm}^{2}\right.$ for Ni-LP, $2.42 \times 10^{-8} \mathrm{~mol} / \mathrm{cm}^{2}$ for Ni-MP, and $2.19 \times 10^{-8} \mathrm{~mol} / \mathrm{cm}^{2}$ for $\mathrm{Ni}-\mathrm{HP})$. Among the three Ni-P samples, the Ni-MP coating shows a higher HER performance than $\mathrm{Ni}-\mathrm{LP}$ and Ni-HP samples because of the small $m$ values of them; but $m$ values of these three Ni-P samples are smaller than that of $\mathrm{Ni}-\mathrm{MP} / \mathrm{MoS}_{2}$. Thus, except for that of the well known commercial $\mathrm{Pt} / \mathrm{C}$, the HER activity of Ni-MP/MoS 2 is most noticeable.
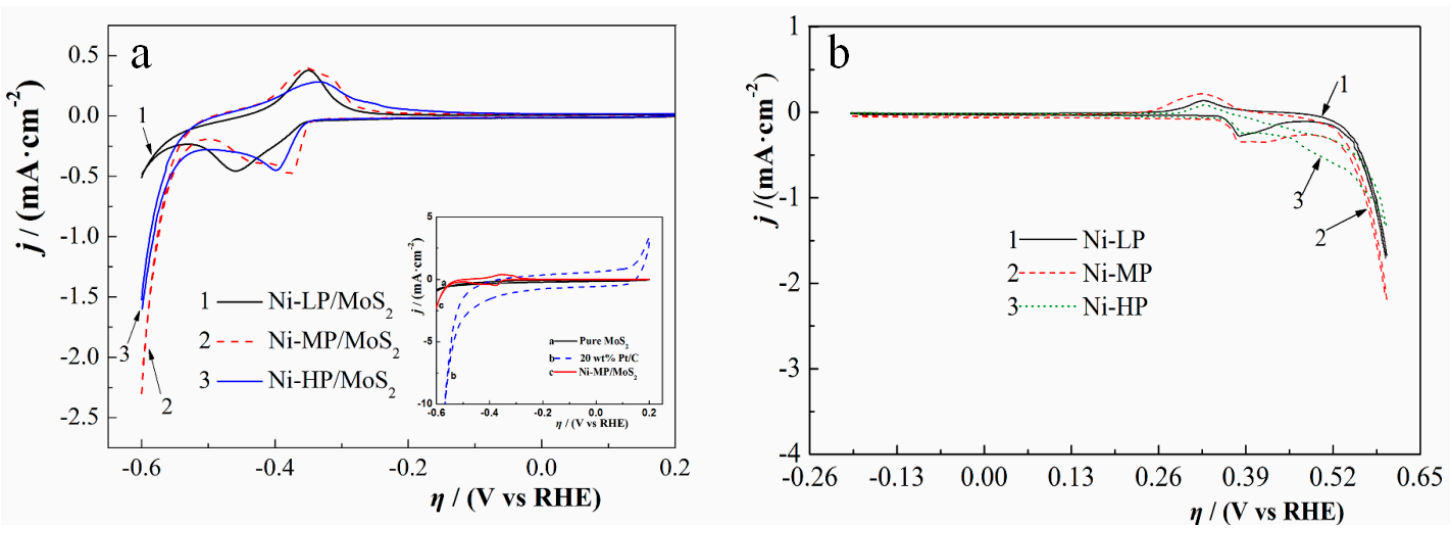

Figure 6. Cyclic voltammetry (CV) curves of the samples: (a) pure $\mathrm{MoS}_{2}, 20 \mathrm{wt} \% \mathrm{Pt} / \mathrm{C}, \mathrm{Ni}-\mathrm{LP} / \mathrm{MoS}_{2}$, $\mathrm{Ni}-\mathrm{MP} / \mathrm{MoS}_{2}$, and $\mathrm{Ni}-\mathrm{HP} / \mathrm{MoS}_{2}$. Scan rate: $10 \mathrm{mV} / \mathrm{s}$, potential window: $-0.6 \sim 0.2 \mathrm{~V}$ (vs. RHE); (b) Ni-LP, Ni-MP, and Ni-HP. Scan rate: $20 \mathrm{mV} / \mathrm{s}$, potential window: $-0.25 \sim 0.6 \mathrm{~V}$ (vs. RHE).

\subsubsection{Electrochemical Impedance Spectroscopy (EIS)}

The obtained Nyquist plots for the three Ni-P/MoS samples are shown in Figure 7. An equivalent circuit model of $R_{\mathrm{s}}\left(Q R_{\mathrm{ct}}\right)$ (where, $R_{\mathrm{s}}$, and $R_{\mathrm{ct}}$ are the solution resistance, and charge transfer resistance; $Q$ presents the constant phase element, CPE) was employed to analyze the electrochemical impedance data. The value of double layer capacity $\left(C_{\mathrm{dl}}\right)$ is calculated using Equation (4).

$$
C_{\mathrm{dl}}=Y_{0} \times\left(R_{\mathrm{s}}^{-1}+R_{\mathrm{ct}}^{-1}\right)^{\mathrm{m}-1}
$$

where, $Y_{0}\left(\mathrm{~S} \mathrm{~s} / \mathrm{cm}^{2}\right)$ is the CPE coefficient in line with the double layer capacitance; $m$, related to the constant phase angle, is the CPE exponent. The EIS data were analyzed by the free-charged Zsimpwin software, and the results are summarized in Table 2. Based on the value of $m$ (ranging from 0.835 to 0.871), CPE shows a capacity nature; the low $R_{\mathrm{S}}$ for all samples indicates the excellent conductivity of the electrolyte. The smaller $R_{\mathrm{ct}}$ and the higher $C_{\mathrm{dl}}$ for the sample of Ni-MP/MoS${ }_{2}$ manifests that this composite owns a more excellent HER property than other two composites. 
In addition, another parameter of exchange current density $\left(j_{0}\right)$ can also be calculated using Equation (5)

$$
j_{0}=\frac{R T}{n_{\mathrm{e}} F R_{\mathrm{ct}}}
$$

where, $n_{\mathrm{e}}$ is the number of transferred electrons, and parameters of $R, T$, and $F$ are already defined by Equation (2). As ascertained by the data (Table 2), without any doubt, the $\mathrm{Pt} / \mathrm{C}$ sample shows the best HER performance followed by the Ni-P/MoS 2 composites and last by $\mathrm{MoS}_{2}$ sample. The three $\mathrm{Ni}-\mathrm{P} / \mathrm{MoS}_{2}$ samples show a larger $j_{0}$ than the virgin $\mathrm{MoS}_{2}$, consistent with the analyses of $R_{\mathrm{ct}}$ and $C_{\mathrm{dl}}$. The value of $j_{0}$ for the $\mathrm{Ni}-\mathrm{MP} / \mathrm{MoS}_{2}$ sample is larger than those of other two composite samples, so the charming HER behavior of $\mathrm{Ni}-\mathrm{MP} / \mathrm{MoS}_{2}$ sample is further validated [37].

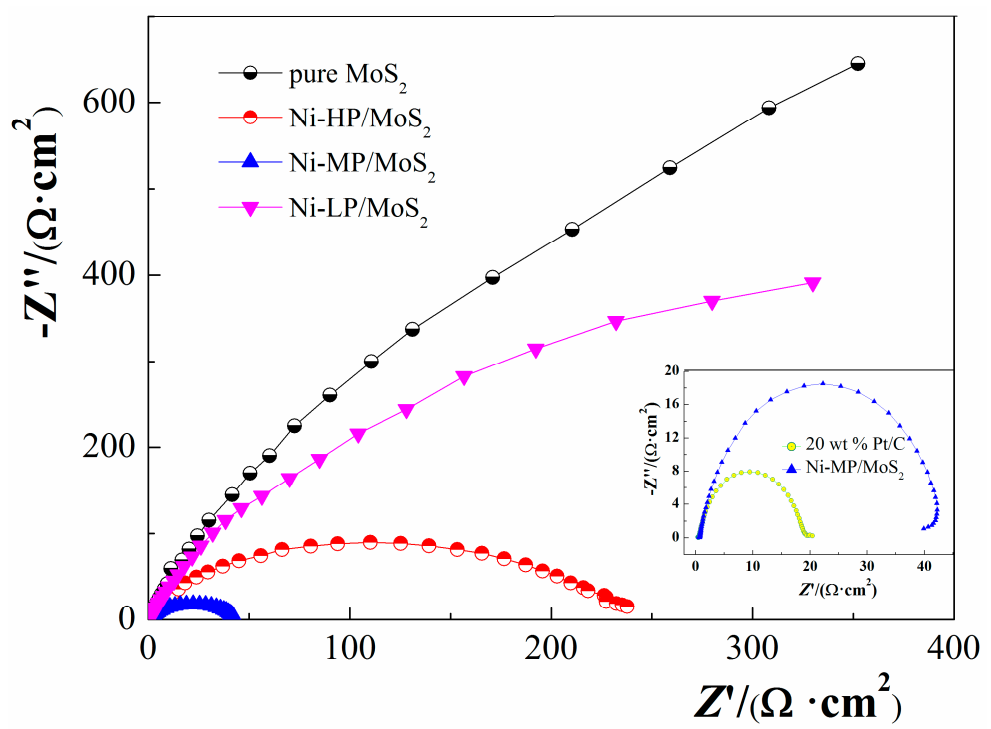

Figure 7. Electrochemical impedance spectroscopy (EIS) curves of the pure $\mathrm{MoS}_{2}, 20 \mathrm{wt} \% \mathrm{Pt} / \mathrm{C}$, $\mathrm{Ni}-\mathrm{LP} / \mathrm{MoS}_{2}, \mathrm{Ni}-\mathrm{MP} / \mathrm{MoS}_{2}, \mathrm{Ni}-\mathrm{HP} / \mathrm{MoS}_{2}$. Cathodic overpotential: $0.7 \mathrm{~V}$ (vs. RHE), frequency: $100 \mathrm{KHz}-10 \mathrm{mHz}$, amplitude of the sinusoidal signal: $5 \mathrm{mV}$.

Table 2. Parameters of solution resistance $\left(R_{\mathrm{S}}\right)$, charge transfer resistance $\left(R_{\mathrm{ct}}\right)$, double-layer capacitance $\left(C_{\mathrm{dl}}\right)$, the dimensionless CPE exponent $m$, and exchange current density $\left(j_{0}\right)$ analyzed from the EIS spectra.

\begin{tabular}{cccccc}
\hline Samples & $\boldsymbol{R}_{\mathbf{s}} /\left(\boldsymbol{\Omega} \cdot \mathbf{c m}^{\mathbf{2}}\right)$ & $\boldsymbol{R}_{\mathbf{c t}} /\left(\boldsymbol{\Omega} \cdot \mathbf{c m}^{\mathbf{2}}\right)$ & $\boldsymbol{m}$ & $\boldsymbol{C}_{\mathbf{d l}} /\left(\times \mathbf{1 0}^{-\mathbf{4}} \cdot \mathbf{F} / \mathbf{c m}^{2}\right)$ & $j_{\mathbf{0}} /\left(\times \mathbf{1 0}^{-\mathbf{5}} \cdot \mathbf{A} / \mathbf{c m}^{\mathbf{2}}\right)$ \\
\hline $\mathrm{MoS}_{2}$ & 0.46 & 3042 & 0.850 & 2.84 & 0.84 \\
$\mathrm{Pt} / \mathrm{C}$ & 0.42 & 19.2 & 0.849 & 51.2 & 133 \\
$\mathrm{Ni}-\mathrm{LP} / \mathrm{MoS}_{2}$ & 0.43 & 2758 & 0.845 & 6.41 & 0.93 \\
$\mathrm{Ni}-\mathrm{MP} / \mathrm{MoS}_{2}$ & 0.60 & 43.2 & 0.871 & 46.0 & 59.4 \\
$\mathrm{Ni}-\mathrm{HP} / \mathrm{MoS}_{2}$ & 0.50 & 239.3 & 0.835 & 7.85 & 8.75 \\
\hline
\end{tabular}

\subsection{HER Stability of the Ni-P/MoS 2 Hybrid Composites}

From an engineering perspective, besides the HER activity, the stability is another essential requirement to guarantee the durability of $\mathrm{Ni}-\mathrm{P} / \mathrm{MoS}_{2}$ composite. Hence, continuous $\mathrm{CV}$ tests for 1000 cycles were carried out at a rate of $50 \mathrm{mV} / \mathrm{s}$ (Figure 8) to evaluate the stabilities of Ni-LP/ $\mathrm{MoS}_{2}$, $\mathrm{Ni}-\mathrm{MP} / \mathrm{MoS}_{2}$, and Ni-HP/MoS composites. As shown in Figure 8, by a comparison of the current density at the initial time and after the long-term test, electrocatalytic behaviors of the three $\mathrm{Ni}-\mathrm{P} / \mathrm{MoS}_{2}$ composites just show a very slight decay, and thereby indicate an excellent HER durability of the composite. For example, the cathodic current density of $\mathrm{Ni}-\mathrm{MP} / \mathrm{MoS}_{2}$ composite only shows a decrease of $4 \%$ ( $\eta=80 \mathrm{mV}$ vs. RHE). In addition, EDS spectra of the Ni-MP/MoS 2 composite before 
and after the stability tests were measured (Figure 9) to monitor the leaching of phosphorus element. As indicated by data reported in Figure 9, about 16.7\% phosphorus element is leached out; thus, in the further research, the enhancement in the stability for the $\mathrm{Ni}-\mathrm{MP} / \mathrm{MoS}_{2}$ sample will be considered.

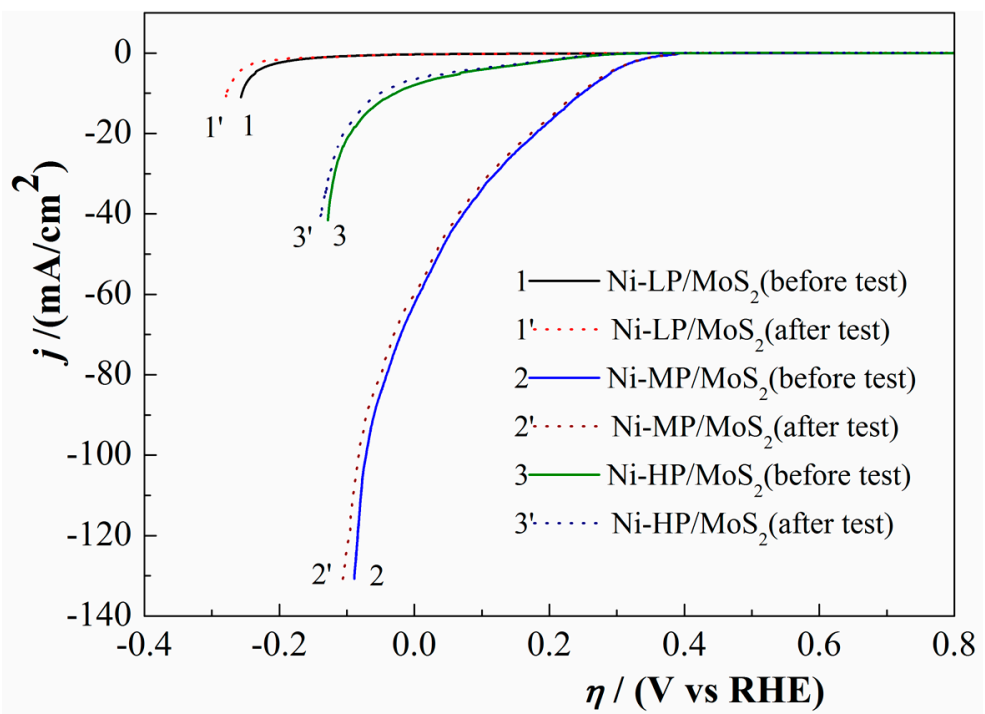

Figure 8. Stability tests for Ni-LP/MoS, $\mathrm{Ni}-\mathrm{MP} / \mathrm{MoS}_{2}$, and $\mathrm{Ni}-\mathrm{HP} / \mathrm{MoS}_{2}$ composites. Scan rate: $50 \mathrm{mV} / \mathrm{s}$; potential window: -0.3 and $0.8 \mathrm{~V}$ (vs. RHE).
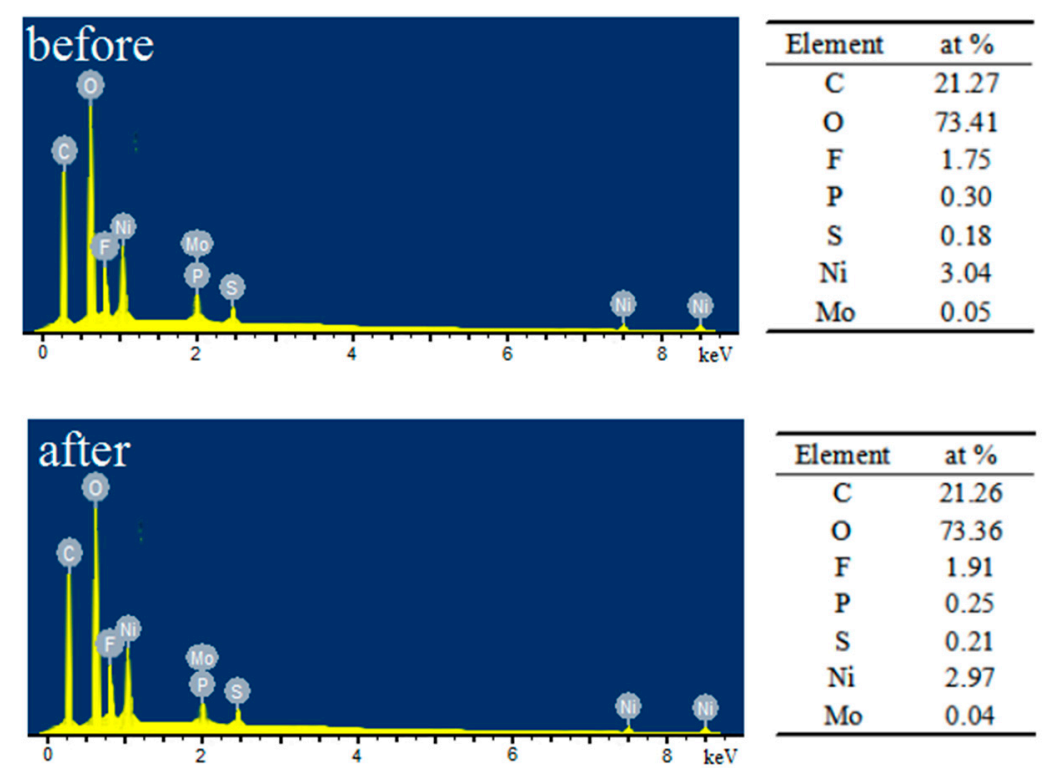

Figure 9. EDS spectra of the $\mathrm{Ni}-\mathrm{MP} / \mathrm{MoS}_{2}$ composite before and after the stability test.

\section{Conclusions}

In summary, three types $\mathrm{Ni}-\mathrm{P}$ coatings (Ni-LP, Ni-MP, and Ni-HP) were anchored to the surface of $\mathrm{MoS}_{2}$ via an electroless plating process. Structures, morphologies, chemical components of the fabricated Ni-LP/MoS $2, \mathrm{Ni}-\mathrm{MP} / \mathrm{MoS}_{2}$, and Ni-HP/MoS composites were characterized. Also, the HER performances of them in $1.0 \mathrm{~mol} / \mathrm{L} \mathrm{KOH}$ solution were evaluated. The main conclusions are shown as follows:

(1) The mixed crystal features for both $\mathrm{Ni}-\mathrm{LP} / \mathrm{MoS}_{2}$ and $\mathrm{Ni}-\mathrm{MP} / \mathrm{MoS}_{2}$, and the amorphous characteristic for Ni-HP/MoS 2 are validated. The phosphorous content of Ni-P coating shows 
a remarkable influence on the crystallinity and the morphology of the $\mathrm{Ni}-\mathrm{P} / \mathrm{MoS}_{2}$ composite. The anchor of Ni-P coatings on the surface of $\mathrm{MoS}_{2}$ is helpful in the enhancement of its HER property, the fabricated $\mathrm{Ni}-\mathrm{P} / \mathrm{MoS}_{2}$ composite shows a more remarkable HER activity than the pure $\mathrm{MoS}_{2}$.

(2) Among the three Ni-P/MoS 2 composites, the HER performance of $\mathrm{Ni}-\mathrm{MP} / \mathrm{MoS}_{2}$ sample is higher than those of other two samples, which is validated by positive onset potential $(\sim 320 \mathrm{mV})$, large cathodic current (100 mA $/ \mathrm{cm}^{2}$ at $\eta=-70 \mathrm{mV}$ vs. RHE), and small Tafel slope ( $\sim 57 \mathrm{mV} /$ decade).

(3) The excellent HER property of Ni-MP/ $\mathrm{MoS}_{2}$ composite can be due to the excellent conductivity of Ni-MP coating, as well as the coexistence of some nickel phosphides.

Acknowledgments: This work was supported by the Hebei Provincial Natural Science Foundation of China (Grant No. B2016203012).

Author Contributions: Jun He prepared the manuscript. Laizhou Song designed this work and gave the guidance for HER evaluation. Jun He and Jiayun Yan analyzed the data and reviewed the manuscript. Ning Kang, Yingli Zhang, and Wei Wang performed the experiments and the measurement of HER. All authors read and approved the manuscript.

Conflicts of Interest: The authors declare no conflict of interest.

\section{References}

1. Wang, D.Z.; Pan, Z.; Wu, Z.Z.; Wang, Z.P.; Liu, Z.H. Hydrothermal synthesis of $\mathrm{MoS}_{2}$ nanoflowers as highly efficient hydrogen evolution reaction catalysts. J. Power Sources 2014, 264, 229-234. [CrossRef]

2. Liu, N.; Yang, L.C.; Wang, S.N.; Zhong, Z.W.; He, S.N.; Yang, X.Y.; Gao, Q.S.; Tang, Y. Ultrathin $\mathrm{MoS}_{2}$ nanosheets growing within an in-situ-formed template as efficient electrocatalysts for hydrogen evolution. J. Power Sources 2015, 275, 588-594. [CrossRef]

3. Min, S.X.; Lu, G.X. Sites for high efficient photocatalytic hydrogen evolution on a limited-layered $\mathrm{MoS}_{2}$ cocatalyst confined on graphene sheets-the role of graphene. J. Phys. Chem. C 2012, 116, 25415-25424. [CrossRef]

4. $\quad$ Dang, H.F.; Qiu, Y.F.; Cheng, Z.Y.; Yang, W.; Wu, H.Y.; Fan, H.B.; Dong, X.F. Hydrothermal preparation and characterization of nanostructured $\mathrm{CNTs} / \mathrm{ZnFe}_{2} \mathrm{O}_{4}$ composites for solar water splitting application. Ceram. Int. 2016, 42, 10520-10525. [CrossRef]

5. Komova, O.V.; Kayl, N.L.; Odegova, G.V.; Netskina, O.V.; Simagina, V.I. Destabilization of $\mathrm{NH}_{3} \mathrm{BH}_{3}$ by water during hydrothermolysis as a key factor in the high hydrogen evolution rates. Int. J. Hydrog. Energy 2016, 41 , 17484-17495. [CrossRef]

6. Frame, F.A.; Osterloh, F.E. CdSe-MoS 2 : A quantum size-confined photocatalyst for hydrogen evolution from water under visible light. J. Phys. Chem. C 2010, 114, 10628-10633. [CrossRef]

7. Cheng, R.L.; Zhang, L.X.; Fan, X.Q.; Shi, J.L. One-step construction of $\mathrm{FeO}_{\mathrm{x}}$ modified g- $\mathrm{C}_{3} \mathrm{~N}_{4}$ for largely enhanced visible-light photocatalytic hydrogen evolution. Carbon 2016, 101, 62-70. [CrossRef]

8. Popczun, E.J.; McKone, J.R.; Read, C.G.; Read, C.G.; Biacchi, A.J.; Wiltrout, A.M.; Lewis, N.S.; Schaak, R.E. Nanostructured nickel phosphide as an electrocatalyst for the hydrogen evolution reaction. J. Am. Chem. Soc. 2013, 135, 9267-9270. [CrossRef] [PubMed]

9. Voiry, D.; Yamaguchi, H.; Li, J.W.; Silva, R.; Alves, D.C.; Fujita, T.; Chen, M.W.; Asefa, T.; Shenoy, V.B.; Eda, G.; et al. Enhanced catalytic activity in strained chemically exfoliated $\mathrm{WS}_{2}$ nanosheets for hydrogen evolution. Nat. Mater. 2013, 12, 850-855. [CrossRef] [PubMed]

10. Zheng, X.L.; Xu, J.B.; Yan, K.Y.; Wang, H.; Wang, Z.L.; Yang, S.H. Space-confined growth of $\mathrm{MoS}_{2}$ nanosheets within graphite: The layered hybrid of $\mathrm{MoS}_{2}$ and graphene as an active catalyst for hydrogen evolution reaction. Chem. Mater. 2014, 26, 2344-2353. [CrossRef]

11. Liu, Y.R.; Hu, W.H.; Li, X.; Dong, B.; Shang, X.; Han, G.Q.; Chai, Y.M.; Liu, Y.Q.; Liu, C.G. Facile one-pot synthesis of $\mathrm{CoS}_{2}-\mathrm{MoS}_{2} / \mathrm{CNTs}$ as efficient electrocatalyst for hydrogen evolution reaction. Appl. Surf. Sci. 2016, 384, 51-57. [CrossRef]

12. Tsai, C.; Abild-Pedersen, F; Nørskov, J.K. Tuning the $\mathrm{MoS}_{2}$ edge-site activity for hydrogen evolution via support interactions. Nano Lett. 2014, 14, 1381-1387. [CrossRef] [PubMed] 
13. Jing, Y.; Ortiz-Quiles, E.O.; Cabrera, C.R.; Chen, Z.F.; Zhou, Z. Layer-by-layer hybrids of $\mathrm{MoS}_{2}$ and reduced graphene oxide for lithium ion batteries. Electrochim. Acta 2014, 147, 392-400. [CrossRef]

14. Liang, T.; Sawyer, W.G.; Perry, S.S.; Sinnott, S.B.; Phillpot, S.R. Energetics of oxidation in $\mathrm{MoS}_{2}$ nanoparticles by density functional theory. J. Phys. Chem. C 2011, 115, 10606-10616. [CrossRef]

15. Xie, J.F.; Zhang, J.J.; Li, S.; Grote, F.B.; Zhang, X.D.; Zhang, H.; Wang, R.X.; Lei, Y.; Pan, B.C.; Xie, Y. Controllable disorder engineering in oxygen-incorporated $\mathrm{MoS}_{2}$ ultrathin nanosheets for efficient hydrogen evolution. J. Am. Chem. Soc. 2013, 135, 17881-17888. [CrossRef] [PubMed]

16. Lukowski, M.A.; Daniel, A.S.; Meng, F.; Forticaux, A.; Li, L.S.; Jin, S. Enhanced hydrogen evolution catalysis from chemically exfoliated metallic $\mathrm{MoS}_{2}$ nanosheets. J. Am. Chem. Soc. 2013, 135, 10274-10277. [CrossRef] [PubMed]

17. Voiry, D.; Salehi, M.; Silva, R.; Fujita, T.; Chen, M.; Asefa, T. Conducting $\mathrm{MoS}_{2}$ nanosheets as catalysts for hydrogen evolution reaction. Nano Lett. 2013, 13, 6222-6227. [CrossRef] [PubMed]

18. Wu, Z.Z.; Fang, B.Z.; Wang, Z.P.; Wang, C.L.; Liu, Z.H.; Liu, F.Y.; Wang, W.; Alfantazi, A.; Wang, D.Z.; Wilkinson, D.P. $\mathrm{MoS}_{2}$ nanosheets: A designed structure with high active site density for the hydrogen evolution reaction. ACS Catal. 2013, 3, 2101-2107. [CrossRef]

19. Wang, H.T.; Lu, Z.Y.; Kong, D.S.; Sun, J.; Hymel, T.M.; Cui, Y. Electrochemical tuning of $\mathrm{MoS}_{2}$ nanoparticles on three-dimensional substrate for efficient hydrogen evolution. ACS Nano 2014, 8, 4940-4947. [CrossRef] [PubMed]

20. Bian, X.J.; Zhu, J.; Liao, L.; Scanlon, M.D.; Ge, P.Y.; Ji, C.; Girault, H.H.; Liu, B.H. Nanocomposite of $\mathrm{MoS}_{2}$ on ordered mesoporous carbon nanospheres: A highly active catalyst for electrochemical hydrogen evolution. Electrochem. Commun. 2012, 22, 128-132. [CrossRef]

21. Chen, Z.B.; Cummins, D.; Reinecke, B.N.; Clark, E.; Sunkara, M.K.; Jaramillo, T.F. Core-shell $\mathrm{MoO}_{3}-\mathrm{MoS}_{2}$ nanowires for hydrogen evolution: A functional design for electrocatalytic materials. Nano Lett. 2011, 11, 4168-4175. [CrossRef] [PubMed]

22. Li, Y.G.; Wang, H.L.; Xie, L.M.; Liang, Y.Y.; Hong, G.S.; Dai, H.J. MoS 2 nanoparticles grown on graphene: An advanced catalyst for the hydrogen evolution reaction. J. Am. Chem. Soc. 2011, 133, 7296-7299. [CrossRef] [PubMed]

23. Li, X.D.; Yu, S.; Wu, S.Q.; Wen, Y.H.; Zhou, S.; Zhu, Z.Z. Structural and electronic properties of superlattice composed of graphene and monolayer MoS 2 . J. Phys. Chem. C 2013, 117, 15347-15353. [CrossRef]

24. Zhang, J.M.; Zhao, L.; Liu, A.P.; Li, X.Y.; Wu, H.P.; Lu, C.D. Three-dimensional $\mathrm{MoS}_{2} / \mathrm{rGO}$ hydrogel with extremely high double-layer capacitance as active catalyst for hydrogen evolution reaction. Electrochim. Acta 2015, 182, 652-658. [CrossRef]

25. Pan, Y.; Yang, N.; Chen, Y.J.; Lin, Y.; Li, Y.P.; Liu, Y.Q.; Liu, C.G. Nickel phosphide nanoparticlesnitrogen-doped graphene hybrid as an efficient catalyst for enhanced hydrogen evolution activity. J. Power Sources 2015, 297, 45-52. [CrossRef]

26. Song, L.Z.; Wang, X.L.; Wen, F.S.; Niu, L.J.; Shi, X.M.; Yan, J.Y. Hydrogen evolution reaction performance of the molybdenum disulfide/nickel-phosphorus composites in alkaline solution. Int. J. Hydrog. Energy 2016, 41, 18942-18952. [CrossRef]

27. Liu, Q.; Gu, S.; Li, C.M. Electrodeposition of nickel-phosphorus nanoparticles film as a Janus electrocatalyst for electro-splitting of water. J. Power Sources 2015, 299, 342-346. [CrossRef]

28. Yu, Q.Y.; Zeng, Z.X.; Zhao, W.J.; Ma, Y.C.; Wu, X.D.; Xue, Q.J. Patterned Ni-P alloy films prepared by "Reducing-Discharging" process and the hydrophobic property. ACS Appl. Mater. Interfaces 2014, 6, 1053-1060. [CrossRef] [PubMed]

29. Wang, H.W.; Skeldon, P.; Thompson, G.E. XPS studies of $\mathrm{MoS}_{2}$ formation from ammonium tetrathiomolybdate solutions. Surf. Coat. Technol. 1997, 91, 200-207. [CrossRef]

30. Koroteev, V.O.; Bulusheva, L.G.; Asanov, I.P.; Shlyakhova, E.V.; Vyalikh, D.V.; Okotrub, A.V. Charge transfer in the $\mathrm{MoS}_{2}$ / carbon nanotube composite. J. Phys. Chem. C 2011, 115, 21199-21204. [CrossRef]

31. Benck, J.D.; Chen, Z.B.; Kuritzky, L.Y.; Forman, A.J.; Jaramillo, T.F. Amorphous molybdenum sulfide catalysts for electrochemical hydrogen production: Insights into the origin of their catalytic activity. ACS Catal. 2012, 2, 1916-1923. [CrossRef]

32. Grosvenor, A.P.; Wik, S.D.; Cavell, R.G.; Mar, A. Examination of the bonding in binary transition-metal monophosphides $\mathrm{MP}(\mathrm{M}=\mathrm{Cr}, \mathrm{Mn}, \mathrm{Fe}, \mathrm{Co})$ by X-ray photoelectron spectroscopy. Inorg. Chem. 2005, 44, 8988-8998. [CrossRef] [PubMed] 
33. Cecilia, J.A.; Infantes-Molina, A.; Rodríguez-Castellón, E.; Jiménez-López, A. A novel method for preparing an active nickel phosphide catalyst for HDS of dibenzothiophene. J. Catal. 2009, 263, 4-15. [CrossRef]

34. Liu, Y.R.; Hu, W.H.; Li, X.; Dong, B.; Shang, X.; Han, G.Q.; Chai, Y.M.; Liu, Y.Q.; Liu, C.G. One-pot synthesis of hierarchical $\mathrm{Ni}_{2} \mathrm{P} / \mathrm{MoS}_{2}$ hybrid electrocatalysts with enhanced activity for hydrogen evolution reaction. Appl. Surf. Sci. 2016, 383, 276-282. [CrossRef]

35. Mech, K.; Żabiński, P.; Kowalik, R.; Tokarski, T.; Fitzner, K. Electrodeposition of Co-Pd alloys from ammonia solutions and their catalytic activity for hydrogen evolution reaction. J. Appl. Electrochem. 2014, 44, 97-103. [CrossRef]

36. Paseka, I. Hydrogen evolution reaction on Ni-P alloys: The internal stress and the activities of electrodes. Electrochim. Acta 2008, 53, 4537-4543. [CrossRef]

37. Manazoğlu, M.; Hapçı, G.; Orhan, G. Effect of electrolysis parameters of Ni-Mo alloy on the electrocatalytic activity for hydrogen evaluation and their stability in alkali medium. J. Appl. Electrochem. 2016, 46, 191-204. [CrossRef]

(C) 2017 by the authors. Licensee MDPI, Basel, Switzerland. This article is an open access article distributed under the terms and conditions of the Creative Commons Attribution (CC BY) license (http:/ / creativecommons.org/licenses/by/4.0/). 